\title{
Carrier gas effects on the SiGe quantum dots formation
}

\author{
C.-H. Lee ${ }^{a}$, C.-Y. Yu ${ }^{a}$, C.M. Lin ${ }^{a}$, C.W. Liu ${ }^{\text {a,b,* }}$, H. Lin ${ }^{c}$, W.-H. Chang ${ }^{c}$ \\ ${ }^{a}$ Department of Electrical Engineering and Graduate Institute of Electronics Engineering, National Taiwan University, Taipei, Taiwan, ROC \\ ${ }^{\mathrm{b}}$ National Nano Device Laboratories, Hsinchu, Taiwan, ROC \\ ${ }^{\mathrm{c}}$ Department of Electrophysics, National Chiao Tung University, Hsinchu, Taiwan, ROC
}

\section{A R T I C L E I N F O}

\section{Article history:}

Available online 18 March 2008

\section{PACS:}

68.65.Ac

68.65. Hb

68.55.-a

66.30.-h

\section{Keywords:}

Carrier gas effect

SiGe quantum dot

Hydrogen passivation

Surface mobility

UHVCVD

\begin{abstract}
A B S T R A C T
SiGe quantum dots (QDs) grown by ultra-high vacuum chemical vapor deposition using $\mathrm{H}_{2}$ and $\mathrm{He}$ carrier gases are investigated and compared. SiGe QDs using He carrier gas have smaller dot size with a better uniformity in terms of dot height and dot base as compared to the $\mathrm{H}_{2}$ carrier gas. There is a higher $\mathrm{Ge}$ composition and less compressive strain in the SiGe QDs grown in He than in $\mathrm{H}_{2}$ as measured by Raman spectroscopy. The Ge content is higher for He growth than $\mathrm{H}_{2}$ growth due to hydrogen induced $\mathrm{Si}$ segregation and the lower interdiffusivity caused by the more strain relaxation in the He-grown SiGe dots. The photoluminescence also confirms more compressive strain for $\mathrm{H}_{2}$ growth than He growth. Hydrogen passivation and Ge-H cluster formation play an important role in the QDs growth.
\end{abstract}

(c) 2008 Elsevier B.V. All rights reserved.

\section{Introduction}

Self-assembled SiGe quantum dots (QDs) have attracted much interest in the potential applications in nanoelectronics and optoelectronics recently. To meet the requirement of device applications, size and shape uniformity are the two most important parameters to be considered. Influences of temperature [1], wettinglayer growth [2], and Si capping [3] on dot size and dot shape have been reported in previous works. Carrier gases such as $\mathrm{He}$ [4], $\mathrm{H}_{2}[5]$, and $\mathrm{N}_{2}$ [6], have been used in the process to control the partial pressure of precursors. However, the comparison of different carrier gases was not reported yet. In this work, morphologies of SiGe QDs grown in $\mathrm{He}$ and $\mathrm{H}_{2}$ were characterized by atomic force microscopy (AFM) and high-angle annular dark-field scanning transmission electron microscopy (HAADF-STEM). Strain relaxation and Ge composition were investigated through Raman spectroscopy, low temperature photoluminescence (PL) measurement, and energy dispersive X-ray spectroscopy (EDS). Moreover, a simple epitaxial model is proposed for He and $\mathrm{H}_{2}$ growth.

\footnotetext{
* Corresponding author at: Department of Electrical Engineering and Graduate Institute of Electronics Engineering, National Taiwan University, No. 1, Sec. 4 Roosevelt Road, Taipei 10617, Taiwan, ROC. Tel.: +886 2 23635251x515; fax: +886 223638247

E-mail address: chee@cc.ee.ntu.edu.tw (C.W. Liu).
}

\section{Experimental procedures}

SiGe QDs were grown by ultra-high vacuum chemical vapor deposition (UHV/CVD) at $600{ }^{\circ} \mathrm{C}$. The base pressure of our UHVCVD system was ultra-high vacuum of $10^{-9}$ Torr. Pure silane $\left(\mathrm{SiH}_{4}\right)$ and germane $\left(\mathrm{GeH}_{4}\right)$ were used as reactant gases, and the gas flow ratio of $\mathrm{GeH}_{4}$ and carrier gases $\left(\mathrm{H}_{2}\right.$ and $\left.\mathrm{He}\right)$ was fixed at $100 \mathrm{sccm} /$ $100 \mathrm{sccm}$ for QDs growth. Before the epitaxial growth, Si wafers were dipped in $10 \% \mathrm{HF}$ solution to remove the native oxide. $\mathrm{No} \mathrm{SiH}_{4}$ was used during QDs growth. Due to the Si/Ge interdiffusion at $600{ }^{\circ} \mathrm{C}$, Ge layers transformed into SiGe alloys. After the deposition of $\sim 60$-nm-thick $\mathrm{Si}$ buffer layer using the $\mathrm{SiH}_{4}$ flow rate of $100 \mathrm{sccm}, 1$-layer and 5-layers QDs were grown. Finally, a $\sim 15-\mathrm{nm}$ Si cap layer using $\mathrm{SiH}_{4}$ flow rate of $100 \mathrm{sccm}$ was grown on top of the SiGe QDs layer to avoid oxidation of the SiGe surface. Note that there were no carrier gases during the Si buffer layer and Si cap layer growth. In this work, we used pure germane for the reactant gas instead of dilute germane in $\mathrm{He}$ or $\mathrm{H}_{2}$, and the gas flow maintained at $100 \mathrm{sccm}$ for QDs growth. The Ge partial pressure should be the same for $\mathrm{H}_{2}$ and $\mathrm{He}$ growth. For the SiGe quantum well growth at $500{ }^{\circ} \mathrm{C}$, the thickness of SiGe film is $\sim 3 \mathrm{~nm}$ for both He growth and $\mathrm{H}_{2}$ growth. The carrier gas effect on the Ge growth rate seems similar in this work. Variations in Ge composition, dot density and strain are due to the surface effect instead of the Ge partial pressure (dose). 


\section{Results and discussion}

Morphologies of 1-layer SiGe QDs without Si capping layer grown in $\mathrm{He}$ and in $\mathrm{H}_{2}$ have been observed by AFM (Fig. 1). Average dot heights are 10 and $12 \mathrm{~nm}$ for $\mathrm{He}$ and $\mathrm{H}_{2}$ growth, while average dot bases are 88 and $89 \mathrm{~nm}$ for $\mathrm{He}$ and $\mathrm{H}_{2}$ growth, respectively. Dot densities are similar $\left(\sim 1.1 \times 10^{10} \mathrm{~cm}^{-2}\right)$ for He-grown sample and $\mathrm{H}_{2}$-grown sample. The average dot height indicates that $\mathrm{H}_{2}$-grown sample can have slightly taller dots (12 nm height) than He-grown sample (10 nm height) measured by AFM. The HAADF-STEM also shows the similar trend. Dot height distribution (Fig. 2) and dot base distribution (Fig. 3) are different for $\mathrm{H}_{2}$ growth and He growth. For $\mathrm{H}_{2}$-grown sample, the bimodality is clearly evidenced in $\mathrm{H}_{2}$ growth for dot height distribution (Fig. 2(b)), and a broad distribution is observed for dot base (Fig. 3). Standard deviations of dot height are 3.2 and $4.4 \mathrm{~nm}$ for He growth and $\mathrm{H}_{2}$ growth, respectively, and those of dot base are 29 and $41 \mathrm{~nm}$ for He growth and $\mathrm{H}_{2}$ growth, respectively. QDs grown in $\mathrm{He}$ have better uniformity than in $\mathrm{H}_{2}$. Different morphologies are also found through HAADF-STEM images. The scanning transmission electron microscopy of 5-layers QDs grown in $\mathrm{He}$ and $\mathrm{H}_{2}$ are shown in Fig. 4(a) and (b), respectively. The thickness of the Si layer between the SiGe QDs layers is $\sim 60 \mathrm{~nm}$. $\mathrm{H}_{2}$ carrier gas creates taller dots than He carrier gas, consistent with AFM results.

Raman spectra of 5-layers SiGe QDs grown in $\mathrm{He}$ and $\mathrm{H}_{2}$ with $488 \mathrm{~nm}$ laser excitation are shown in Fig. 5 with the resolution of $0.2 \mathrm{~cm}^{-1}$. Besides strong bulk Si signal at $520 \mathrm{~cm}^{-1}$, the $\mathrm{Si}-\mathrm{Ge} 2 \mathrm{TA}$ phonon, Ge-Ge phonon, and $\mathrm{Si}-\mathrm{Ge}$ phonon of dots were also observed. For the peak at $\sim 417 \mathrm{~cm}^{-1}$, QDs contribute more intensity of the Raman spectra than wetting layers. The sample with wetting layers only has very weak intensity at $\sim 417 \mathrm{~cm}^{-1}$. The Si-Ge phonon peak $\left(\sim 417 \mathrm{~cm}^{-1}\right)$ is sensitive to both the strain
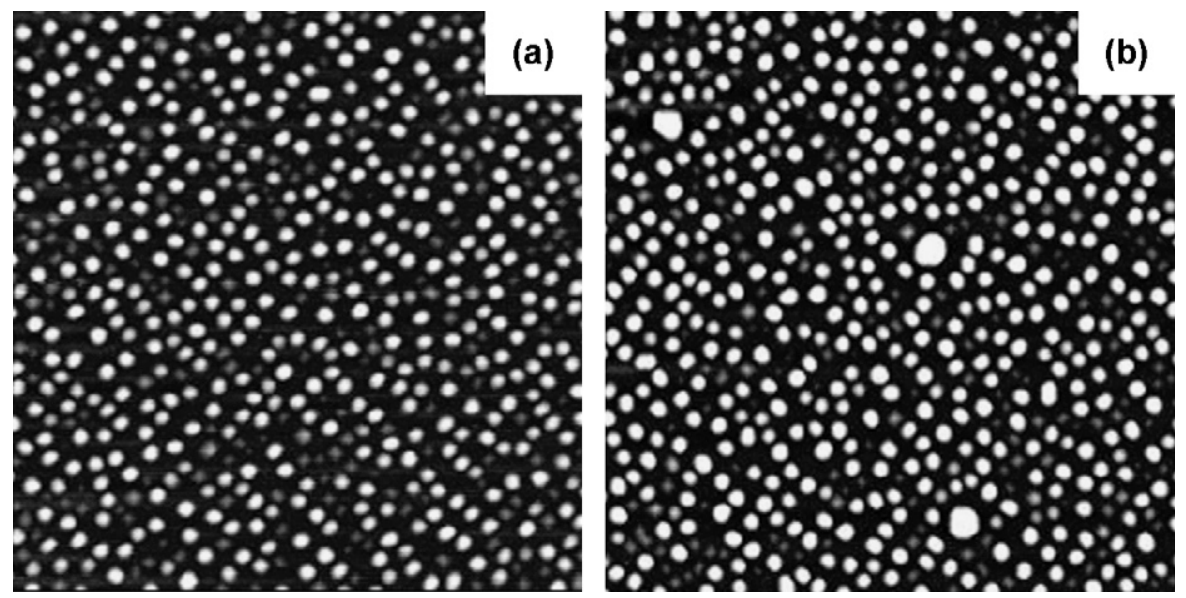

Fig. 1. The $2.5 \mu \mathrm{m} \times 2.5 \mu \mathrm{m}$ AFM image of SiGe QDs grown in different carrier gases: (a) He and (b) $\mathrm{H}_{2}$.

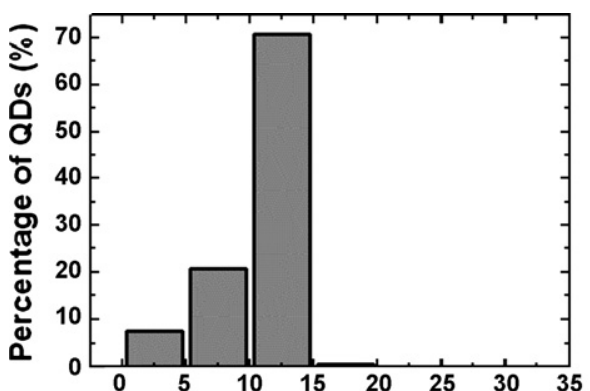

(a)

Dot height $(\mathrm{nm})$

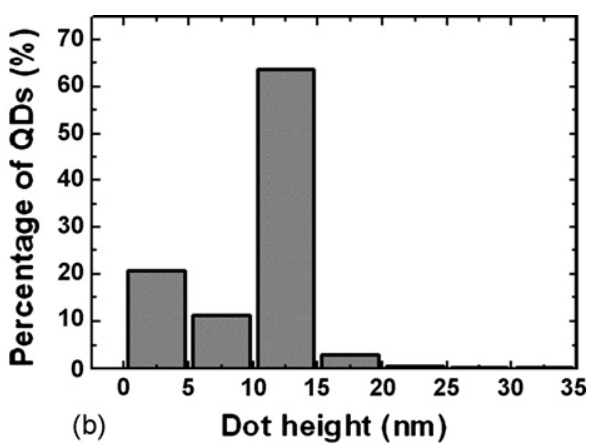

Fig. 2. The dot height distribution of SiGe QDs grown in (a) He and (b) $\mathrm{H}_{2}$. The bimodality is clearly evidenced in $\mathrm{H}_{2}$ growth.
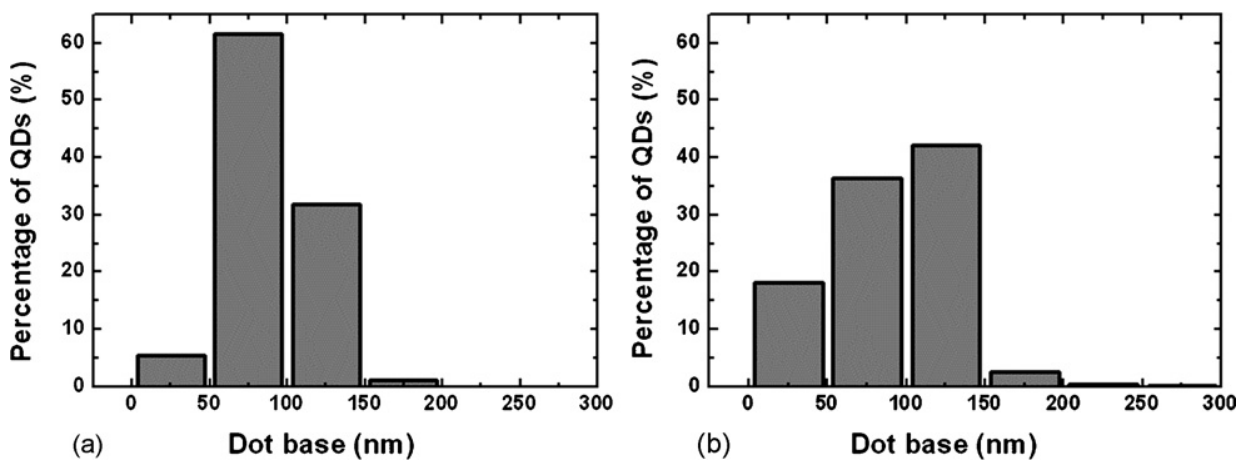

Fig. 3. The dot base distribution of SiGe QDs grown in (a) He and (b) $\mathrm{H}_{2}$. 

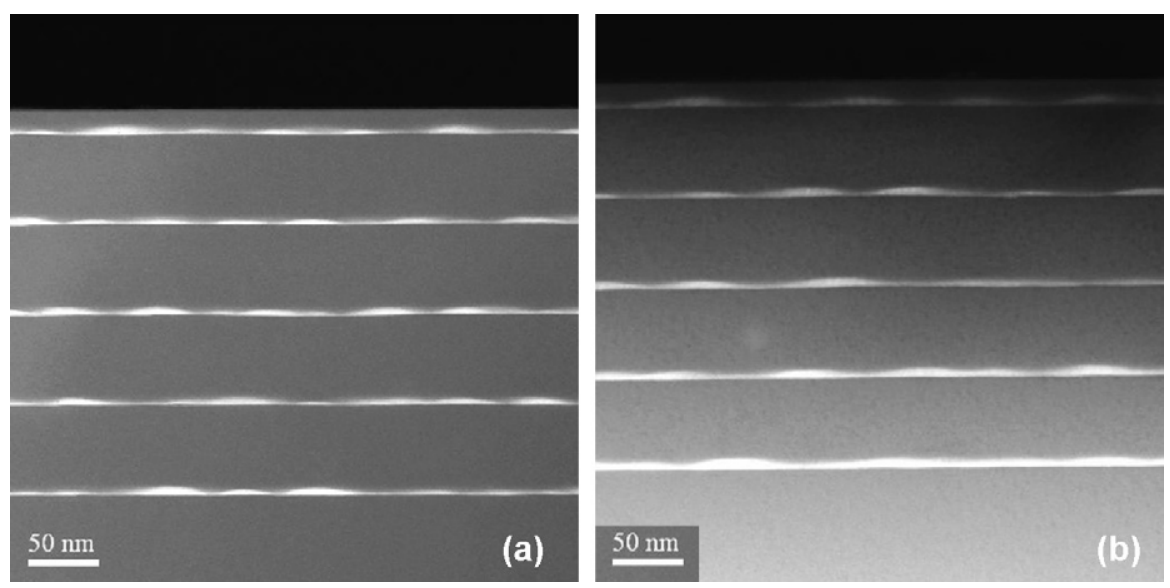

Fig. 4. The HAADF-STEM images of the regular regions of QDs grown in (a) He and (b) $\mathrm{H}_{2}$.

and Ge composition [7]. Both more compressive strain and higher Ge content increase the wave number of this peak. The Si-Ge 2TA phonon peak (at $\sim 220 \mathrm{~cm}^{-1}$ ) is sensitive to only the Ge concentration $[8,9]$. Wave numbers of 2TA mode are $\sim 222$ and $\sim 223 \mathrm{~cm}^{-1}$ for He growth and $\mathrm{H}_{2}$ growth, respectively. Note that the $\sim 1 \mathrm{~cm}^{-1}$ Raman shift between He-grown and $\mathrm{H}_{2}$-grown QDs is well beyond the resolution $\left(0.2 \mathrm{~cm}^{-1}\right)$ of the Raman measurement. The $\sim 1 \mathrm{~cm}^{-1}$ lower in wave number of 2TA mode indicates the average Ge concentration of He-grown SiGe layers is $2 \%$ higher than $\mathrm{H}_{2}$-grown layers [10]. The $\sim 2 \%$ larger Ge content leads to a $\sim 0.6 \mathrm{~cm}^{-1}$ shift of the Raman peak at $\sim 417 \mathrm{~cm}^{-1}$ [11] if lattice strain are the same in He-grown and $\mathrm{H}_{2}$-grown samples. However, wave numbers of $\mathrm{Si}-\mathrm{Ge}$ phonon peaks are both at $\sim 416.5 \mathrm{~cm}^{-1}$ for $\mathrm{He}$ and $\mathrm{H}_{2}$ growth. This result indicates that He-grown QDs have less strain (more relaxation) than $\mathrm{H}_{2}$-grown QDs. The larger $\mathrm{Ge}$ concentration in SiGe QDs grown in He is partly attributed to the highly relaxed nature of the dots. Note that $\mathrm{H}_{2}$ carrier gas can create slightly taller dots than He carrier gas. The smaller dot height in He-grown sample, which corresponds to a smaller contact angle, leads to more relaxation than $\mathrm{H}_{2}$-grown sample due to the decrease of strain energy [12].

Higher Ge content suggested in the Raman measurement is due to suppressed Ge/Si interdiffusion in He-grown QDs. The stronger $\mathrm{Si} / \mathrm{Ge}$ interdiffusion due to larger compressive strain [13] in $\mathrm{H}_{2^{-}}$ grown sample leads to less Ge content, which is consistent with the conclusions from Raman measurement. $\mathrm{H}_{2}$ carrier gas, which increases Si segregation during QDs growth [14] can also be responsible for the smaller $\mathrm{Ge}$ composition in $\mathrm{H}_{2}$-grown sample.

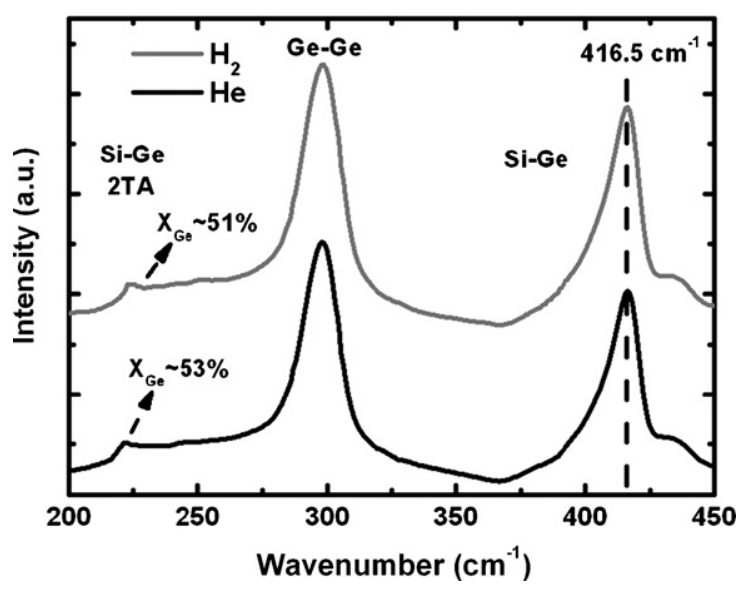

Fig. 5. The Raman spectra of SiGe QDs grown in $\mathrm{He}$ and $\mathrm{H}_{2}$.
Note that the Ge concentration difference between He-grown and $\mathrm{H}_{2}$-grown samples cannot be resolved by EDS. Fig. 6 shows the low temperature $(10 \mathrm{~K})$ PL measurement of 5-layers QDs with He and $\mathrm{H}_{2}$ carrier gases. The PL emission peak of He-grown sample is $\sim 13 \mathrm{meV}$ higher than that of $\mathrm{H}_{2}$-grown sample. Ge concentration and strain might be responsible for the emission peak shift. For the effect of Ge content, the emission peak of He-grown sample should be $\sim 6 \mathrm{meV}$ lower than that of $\mathrm{H}_{2}$-grown sample due to higher $\mathrm{Ge}$ content [15]. However, this is not consistent with the experimental measurement. Strain of $\mathrm{H}_{2}$-grown sample is $\sim 0.11 \%$ higher than that of He-grown sample based on the Raman result [8]. The emission peak of the He-grown sample would be $\sim 12 \mathrm{meV}$ higher than that of $\mathrm{H}_{2}$-grown sample due to less compressive strain in QDs. Considering the effect of Ge content and strain simultaneously, the net emission peak shift is $\sim 6 \mathrm{meV}$. He-grown sample has higher PL emission peak energy than $\mathrm{H}_{2}$-grown sample, which agrees with the experimental data qualitatively. The error of quantitative analysis ( 6 vs. $13 \mathrm{meV}$ ) is probably due to some measurement error, but is not fully understood.

Carrier gas effect plays an important role in the QDs growth. Fig. 7 shows a simple growth model for $\mathrm{H}_{2}$ and He growth. For $\mathrm{H}_{2}$ carrier gas, the $\mathrm{Si}$ surface is passivated by hydrogen due to the adsorption of $\mathrm{H}_{2}$ from the environment [16]. Hydrogen passivation can block the surface sites for dissociative adsorption of germane [17]. $\mathrm{H}_{2}$-rich environment also enhances the $\mathrm{Ge}-\mathrm{H}$ cluster formation, which increases Ge surface mobility [18] and strengthens surface diffusion. $\mathrm{Ge}$ atoms can diffuse on the surface and assemble with other $\mathrm{Ge}$ atoms which have been already adsorbed on surface sites. Never-

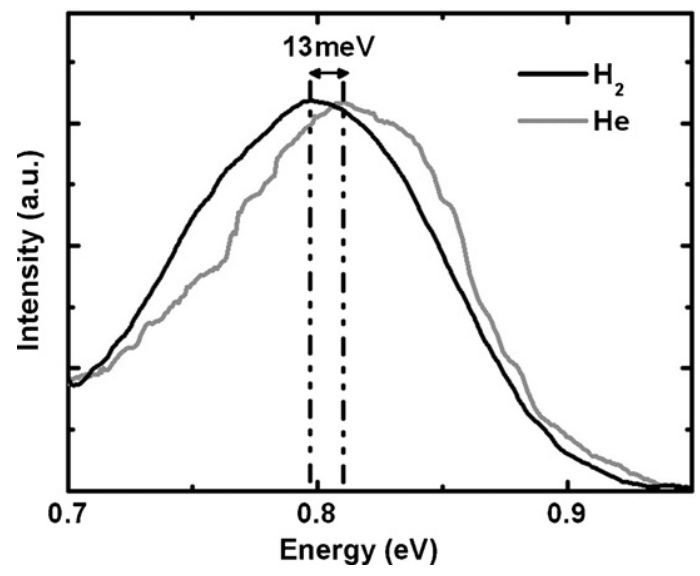

Fig. 6. The PL spectrum of the SiGe dots grown in $\mathrm{He}$ and $\mathrm{H}_{2}$. The $\sim 13 \mathrm{meV}$ variation of the emission peak is caused by the difference in compressive strain. 


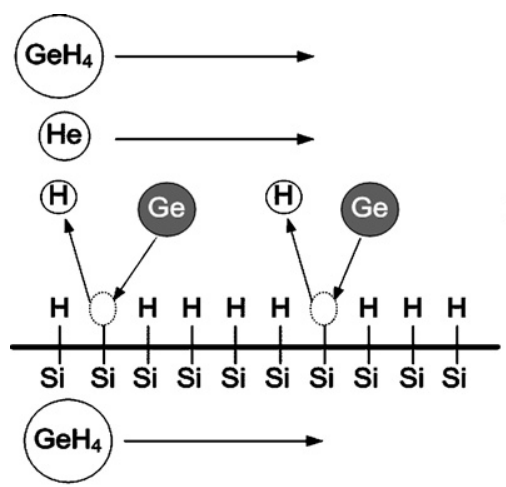

(a)
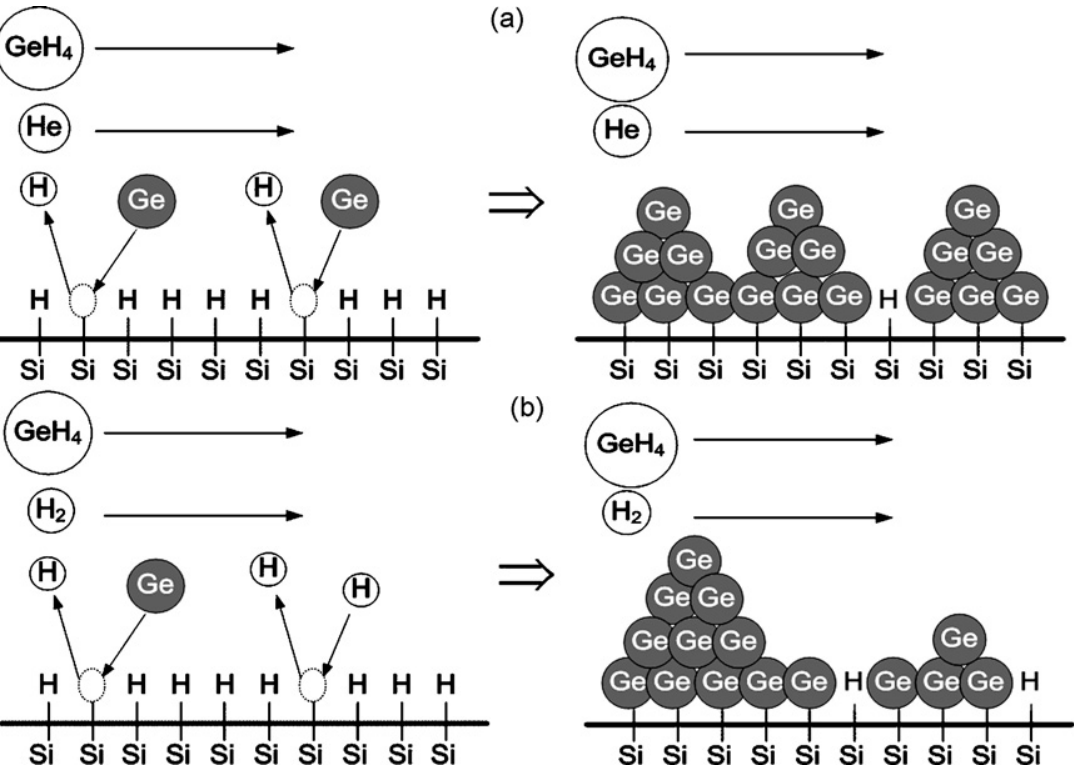

Fig. 7. The growth model of SiGe dots grown in (a) He and (b) $\mathrm{H}_{2}$. The major difference is the hydrogen induced $\mathrm{H}$-passivation on the surface.

theless, for He carrier gas, hydrogen passivation decreases since there are no $\mathrm{H}_{2}$ in the environment. The He carrier gas flow can take away the hydrogen which is desorbed on the surface, and surface mobility can also reduce due to the reduction of $\mathrm{Ge}-\mathrm{H}$ cluster. Therefore, $\mathrm{H}_{2}$ carrier gas creates taller dots and worse uniformity in dots distribution than He carrier gas.

\section{Conclusion}

In conclusion, morphologies, compressive strain and $\mathrm{Ge}$ composition of QDs in $\mathrm{He}$ and in $\mathrm{H}_{2}$ carrier gases are studied. The He growth has a smaller dot size and a better uniformity in dots height and base width distribution than $\mathrm{H}_{2}$ growth. Raman results show higher Ge concentration and more relaxation in 5layers QDs layer grown in He as compared to those grown in $\mathrm{H}_{2}$ carrier gas. Higher dot density for He growth leads to a larger strain relaxation in SiGe layer as compared to $\mathrm{H}_{2}$ growth. Hydrogen induced $\mathrm{Si}$ segregation and slower $\mathrm{Si} / \mathrm{Ge}$ interdiffusion due to smaller strain are responsible for the lower Ge content in Hegrown sample. PL spectra also confirm smaller compressive in Hegrown sample. Hydrogen passivation during the process and $\mathrm{Ge}-\mathrm{H}$ cluster formation should be responsible for the difference between He growth and $\mathrm{H}_{2}$ growth.

\section{Acknowledgements}

The authors would like to acknowledge Dr. Yung-Hui Yeh and Mr. H. T. Chen at the DTC/ITRI for the Raman measurement, and D.
J. Lockwood, J. -M. Baribeau and X. Wu at the National Research Council of Canada for the HAADF-STEM measurement. This work was supported by National Nano Device Laboratories and National Science Council of ROC under contract no. 95-2221-E-002-370.

\section{Reference}

[1] G. Jin, J.L. Liu, K.L. Wang, Appl. Phys. Lett. 83 (2003) 2847.

[2] H.J. Kim, Y.H. Xie, Appl. Phys. Lett. 79 (2001) 263.

[3] Y.Q. Wu, F.H. Li, J. Cui, J.H. Lin, R. Wu, J. Qin, C.Y. Zhu, Y.L. Fan, X.J. Yang, Z.M. Jiang, Appl. Phys. Lett. 87 (2005) 223116.

[4] S.W. Lee, P.S. Chen, T.Y. Chien, L.J. Chen, C.T. Chia, C.W. Liu, Thin Solid Films 508 (2006) 120.

[5] B.S. Meyerson, Appl. Phys. Lett. 48 (1986) 797.

[6] P. Meunier-Beillard, M. Caymax, K. Van Nieuwenhuysen, G. Doumen, B. Brijs, M. Hopstaken, L. Geenen, W. Vandervorst, Appl. Surf. Sci. 224 (2004) 31.

[7] M. Stoehr, D. Aubel, S. Juillaguet, J.L. Bischoff, L. Kubler, D. Bolmont, F. Hamdani, B. Fraisse, R. Fourcade, Phys. Rev. B 53 (1996) 6923.

[8] P.H. Tan, K. Brunner, D. Bougeard, G. Abstreiter, Phys. Rev. B 68 (2003) 125302.

[9] M.H. Liao, C.-H. Lee, T.-A. Hung, C.W. Liu, J. Appl. Phys. 102 (2007) 053520.

[10] J.S. Lannin, Phys. Rev. B 16 (1977) 1510.

[11] J.-M. Baribeau, X. Wu, D.J. Lockwood, J. Vac. Sci. Technol. A 24 (2006) 663.

[12] H.T. Johnson, L.B. Freund, J. Appl. Phys. 81 (1997) 6081.

[13] G. Xia, M. Canonico, J.L. Hoyt, International SiGe Technology and Device Meeting (ISTDM), 2006.

[14] E. Rudkevich, F. Liu, D.E. Savage, T.F. Kuech, L. McCaughan, M.G. Lagally, Phys. Rev. Lett. 81 (1998) 3467.

[15] J.-P. Noël, N.L. Rowell, D.C. Houghton, D.D. Perovic, Appl. Phys. Lett. 57 (1990) 1037

[16] P. Bratu, W. Brenig, A. Groß, M. Hartmann, U. Höfer, P. Kratzer, R. Russ, Phys. Rev. B 54 (1996) 5978

[17] R. Larciprete, S. Cozzi, E. Masetti, M. Montecchi, G. Padeletti, Thin Solid Films 315 (1998) 49.

[18] A. Nayfeh, C.O. Chui, K.C. Saraswat, T. Yonehara, Appl. Phys. Lett. 85 (2004) 2815. 